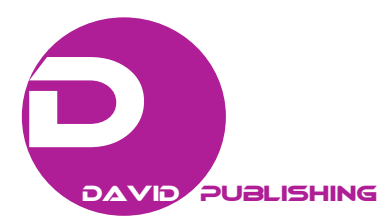

\title{
The Physical Profile of Elite Boardercross
}

\section{Snowboarders}

\author{
Elliot Smith, Abigail Larson and Mark DeBeliso \\ Department of Physical Education and Human Performance, Southern Utah University, Cedar City, UT 84720, USA
}

\begin{abstract}
Boardercross Snowboarding is an increasingly popular sport where snowboarders race through a downhill course for the fastest time. Boardercross has recently become an Olympic Sport; however, limited data exists regarding these athletes' physical characteristics. This study gathered data to further define the physical profile of an elite boardercross snowboarder so that coaches and athletes will be more able to set training benchmarks and identify athlete potential. NorAm level boardercross snowboarders $(n=10$ males; $n=9$ females) completed a series of tests designed to measure anthropometrics and parameters important to physical performance. Each participant's height and weight were measured using a scale and tape measure. Body fat percentage was measured using skin fold calipers. The Modified Bass test (MBASS) was used to measure dynamic balance. A jump height test was used to access leg power. A T-Test was used to measure speed and agility. A one minute $12 \mathrm{inch}$ soft hurdle jump test was used to measure lower body muscular endurance. A one minute sit-up test was used to measure core endurance. Average height and weight for males was $176.4 \pm$ $7.0 \mathrm{~cm}$ and $75.4 \pm 11.3 \mathrm{~kg}$; average height and weight for females was $164.1 \pm 6.1 \mathrm{~cm}$ and $60.8 \pm 10.2 \mathrm{~kg}$. Average body fat percentage for males and females was $11.6 \% \pm 4.5 \%$ and $18.9 \% \pm 6.4 \%$, respectively. Male MBASS error score dominant leg average was $23.1 \pm$ 22.4 and non-dominant leg average was $33.9 \pm 22.5$; female MBASS error score was dominant leg $15.9 \pm 16.67$ and non-dominant leg was $31.1 \pm 25.21$. Male leg power was $1,538.2 \pm 334.8$ watts and peak leg power was $4,402.9 \pm 722.7$ watts. Female leg power was $778.2 \pm 216.1$ watts, peak leg power was 2,634.6 \pm 350.1 watts. Male and female T-test times were $11.43 \pm 0.60$ and $12.57 \pm 0.89$ seconds, respectively. Leg endurance test scores were $85.3 \pm 14.0$ (male) and $59.6 \pm 8.4$ (female) jumps. Male and female core endurance test scores were $37.8 \pm 8.4$ and $36.9 \pm 6.5$ sit-ups, respectively. In the future, additional data sets from other boardercross athletes should be added to this existing set and attempt to quantify the relationship between physical performance measures (as collected in this study) and actual NorAm competition rankings.
\end{abstract}

Key words: Snowboard, boardercross, elite, speed, agility, balance.

\section{Introduction}

Snowboarding's popularity has grown rapidly since the early 1980's and has diversified into several different areas of specialty. One area of snowboarding that has gained popularity is what has become known as "boardercross", which is a freestyle race over terrain designed with jumps, hills, rollers, steeps, and flats. This form of competition is a combination of fast alpine snowboarding and freestyle snowboarding [1]. In 2006, the sport of boardercross was added to the Olympic Games and has further gained popularity [2].

In competition, generally 4-6 snowboarders start at a

Corresponding author: Mark DeBeliso, Ph.D., research fields: orthopedic biomechanics, mechanics and metabolics of sport movements and work-tasks, strength training for all walks of life, and master's athletes. gate simultaneously and race down the hill to the finish line at the bottom of the course [1]. The terrain is designed to challenge the control of snowboarders while they race for the fastest time. Boardercross snowboarding is a highly physically demanding sport requiring, balance, technique, power, endurance, and strength. Although normative athlete data has been established for many different sports [3-5], few studies have observed the physical characteristics of elite boardercross snowboarders [6, 7].

The purpose of this study was to obtain physical characteristics of highly trained boardercross snowboarders. With this knowledge, coaches and athletes will be better able to set training goal benchmarks and coaches will be better able to identify 
individuals who have potential to succeed at a high level of competition. The current study obtained data for several measurable characteristics including height, body mass, body fat percentage, speed and agility, leg power, dynamic balance, leg muscular endurance, and core endurance.

\section{Methods}

\subsection{Participants}

The participants were members of Auburn Ski Club, Park City Ski Team, Team Utah Boardercross, and Squaw Valley Snowboard Team. Each participant was competing at the NorAm level of competition and many were working towards making the U.S. National Team. Participants were recruited via word of mouth by contacting the Team coaches. Permission to conduct the study was obtained through a University Institutional Review Board. Each participant and parent gave written consent before engaging in the study. Parent/guardian permission was obtained prior to testing if a participant was under the age of 18. All participants were injury free at the time of testing and were cleared by their coaches for participation.

\subsection{Procedures}

At the beginning of the day of testing, each participant's body composition was evaluated. Body composition testing was based on the American College of Sports Medicine guidelines for exercise testing and involved measuring and obtaining each participant's height, mass, and skinfold measurements [8].

Weight was measured using a standard scale (TanitaBF-682W). Height was measured using a tape measure. Body fat percentage was determined using skinfold measurements from three sites on the right side of each participant's body using Lange skinfold calipers [8]. Male participants had skinfold measurements taken from the chest, abdomen, and thigh. Female participants had skinfold measurements taken from the triceps, suprailiac, and thigh [8]. Skin fold caliper tests are considered a valid and reliable method of measuring body fat percentage [9]. The following formulas were used to convert the skinfolds to estimates of body fat percentages [8]:

Male body density $=1.0938-0.0008267$ (sum of the three skinfolds) +0.0000016 (sum of the three skinfolds) $)^{2}-0.0002574$ (age)

Female body density $=1.099421-0.0009929$ (sum of the three skinfolds) +0.0000023 (sum of the three skinfolds) ${ }^{2}-0.00012828$ (age)

Body Fat $\%=(495 /$ body density $)-450$

Following the body measurements, participants performed the physical performance tests. The participants performed a warm up, including a light jog and/or dynamic stretching, prior to testing. Following the warm-up, the tests were performed in the following order: dynamic balance (MBASS test), lower body power (jumping test), speed and agility (T-Test), lower body endurance (soft hurdle test), and core endurance (sit-up test). The tests were administered approximately 10 minutes apart. All of the tests were administered by the same tester with the exception on the MBASS test.

\subsection{Dynamic Balance}

The Modified Bass test (MBASS) was selected to assess dynamic balance. Athletic or masking tape was placed on the ground in one inch squares in a course as shown in Fig. 1. The participant jumped from square to square on one leg with hands on hips [10]. On each landing the participant attempted to look forward without moving the support leg [10]. The participant jumped to a new square every five seconds [10].

The MBASS test is scored based on frequency of errors made by the participant [10]. Two types of errors can be made; the first type of error is considered to be a "landing error" and occurs in the event of the participant's foot not landing on the tape, not facing forward, or if the participant stumbles [10], each occurrence is assessed at 10 points [10]. The second type of error is considered a "balancing error" and occurs 


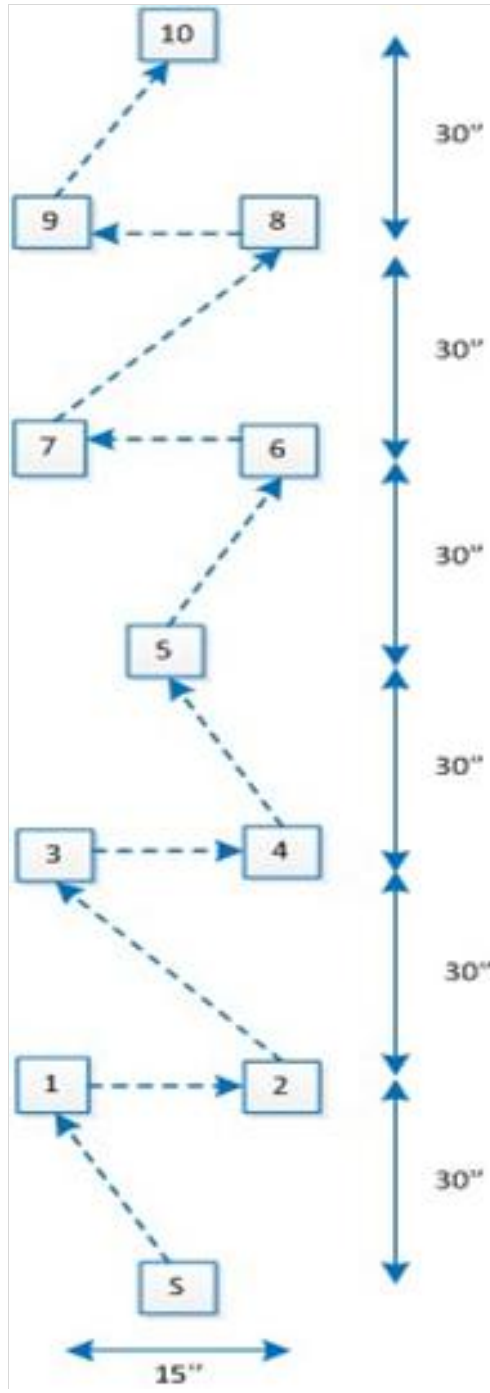

Fig. 1 MBASS course pathway.

when a participant takes his or her hand off the hips or if the non-testing leg/foot touches the floor, the opposite leg, or moves into excessive flexion, extension, or abduction; each occurrence is assessed at three points and all points are combined for a total score [10].

Each participant was given two familiarization sessions [10]. A stopwatch was used to time intervals between jumps. Each participant was tested using both the self-designated dominant and non-dominate leg.

The MBASS is considered a reliable measurement of dynamic balance [11] and the National Strength and Conditioning Association recommends the test in its NSCA's Guide to Tests and Assessment [10]. However, it should be noted that there is some subjectivity on the part of the test administrator in regards to what constitutes excessive flexion, extension, or abduction.

\subsection{Lower Body Power}

A vertical jump test was used to measure each participant's leg power. This test had an athlete stand with his or her dominant shoulder approximately six inches from a wall [12]. The participant had his or her hand covered with chalk and was instructed to reach up and mark as high as possible on the wall while holding both feet flat on the floor [12]. After the wall was marked, the participant jumped as high as possible without taking any steps but using a counter-movement [12]. At the height of the jump the participant made a second mark on the wall [12]. The difference between the two marks represented the participant's jump height [12]. The best of three trials was recorded [12].

Since the vertical jump only measured jump height and did not take into account the weight of a participant, a formula was used to convert jump height to power. The following two formulas, developed by Harman and colleagues, were used to convert the measurement [12]:

Peak power $=61.9$ (jump height $)+36$ (body mass $)-$ 1,822

Mean power $=21.2$ (jump height $)+23$ (body mass) $-1,393$

Power is measured in Watts (W), jump height is measured in centimeters $(\mathrm{cm})$, and body mass is measured in kilograms $(\mathrm{kg})$. Harman and colleagues found using the above conversion formula to be particularly effective when estimating peak jumping power [12].

\subsection{Speed and Agility}

The speed and agility of each participant was measured using the T-test. This test is a four directional test that effectively measures ability to move quickly in several directions [13]. The set-up involves four cones placed in the shape of a "T" as shown in the Fig. 2 [14]. The test begins with the participant starting at cone "A" 


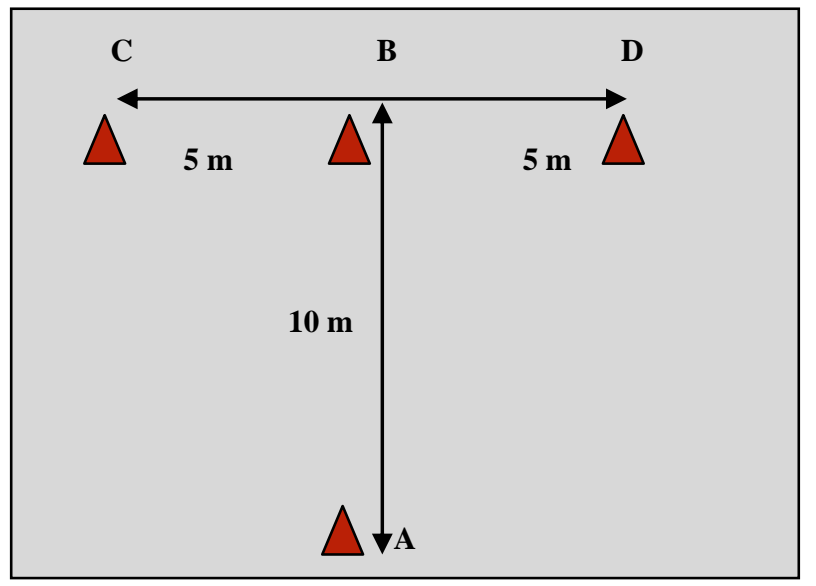

Fig. 2 T-test course pathway.

and sprinting forward and to touch the base of cone " $\mathrm{B}$ " [14]. From cone "B" the participant shuffles left towards cone " $\mathrm{C}$ " and touches the cone with his or her nearest hand, while not crossing feet and continuing to face forward [14]. Once the participant touches the base of cone "C," the participant shuffles right and touches the base of cone " $D$ " [14]. Next the participant shuffles back to cone " $\mathrm{B}$ " touches its base and then runs backwards past cone " $A$ " [14]. The course is set up on a wood floor, and a stopwatch measures the time of the participant. The participant must redo the test if he or she fails to touch any cone [14]. A study performed by Pauole and colleagues [13] found the $\mathrm{T}$-Test to be a reliable and accurate measurement of an athlete's agility, speed, and leg power.

\subsection{Lower Body Muscular Endurance}

A one minute jump endurance test was used to measure the lower body muscular endurance of each participant [15]. The participant began with both feet on the ground, perpendicular to a $30.5 \mathrm{~cm}$ (12 inch) soft agility hurdle [15]. Once the participant was ready, he or she jumped off both feet back and forth over the hurdle as many times as possible for 60 seconds [15]. Traditionally the test duration is 30 seconds; however, for the purpose of this study, the test was lengthened to 60 seconds in order to further stratify the participants and provide more useful data. The total jumps during the one minute were the participant's score. A stopwatch was used to time the test. Pupo and colleagues [15] showed that a jump test of this type is a reliable and valid method for determining lower body muscular endurance.

\subsection{Core Endurance}

A standard one minute sit-up test was conducted by each participant to measure core muscular endurance. Each participant laid down on a mat with his or her knees bent at right angles with the feet of each participant held down by an assistant. The fingers of each participant were interlocked behind the head. The participant then had one minute to perform as many sit-ups as possible.

A sit-up was not counted if the upper body was not vertical upon completion, or if the back did not touch the floor prior to ascent. The score of the participant was the number of sit-ups performed during the one-minute test. The participants laid on a one inch soft mat for cushion during the test. A stopwatch was used to time the test. The one-minute sit-up test has been shown to be a valid and reliable measure of core stability [16].

\subsection{Statistical Analysis}

Means and standard deviations were calculated for each variable measured. Frequency histograms were used to explore variable normalcy [17]. Independent t-tests were used to determine if differences were present between genders. Statistics were calculated in Excel 2013 and frequency histograms were explored in a spreadsheet prepared by McDonald [17].

\section{Results}

The study included 10 male and 9 female participants. The mean age of the male participants was $21.4 \pm 5.4$ years while the mean age of the female participants was $19.9 \pm 3.8$ years. The mean \pm standard deviation for age, height, body mass, body mass index (BMI), and body composition of the participants is presented in Table 1. All of the participants completed 
all of the physical tests without complication except one female participant who did not complete the MBASS, T-test, and the 60-second jump test.
Figs. 3-7 display the scores for the T-test, MBASS, endurance hurdle test, and one-minute sit-up test for male and female participants.

Table 1 Participant descriptive information.

\begin{tabular}{lll}
\hline Measurement & Female $(n=9)$ & Male $(n=10)$ \\
\hline Age & $21.4 \pm 5.4$ & $19.9 \pm 3.8$ \\
Body height $(\mathrm{cm})$ & $164.1 \pm 2.4$ & $176.4 \pm 7.0$ \\
Body mass $(\mathrm{kg})$ & $60.8 \pm 10.2$ & $75.4 \pm 11.3$ \\
Body fat \% & $18.8 \pm 6.4^{*}$ & $11.6 \pm 4.5$ \\
Body Mass Index & $22.5 \pm 2.8$ & $24.22 \pm 3.3$ \\
\hline
\end{tabular}

NorAm Boardercross Snowboarders (mean $\pm \mathrm{sd}$ ), *Significant difference between genders $P<0.01$.

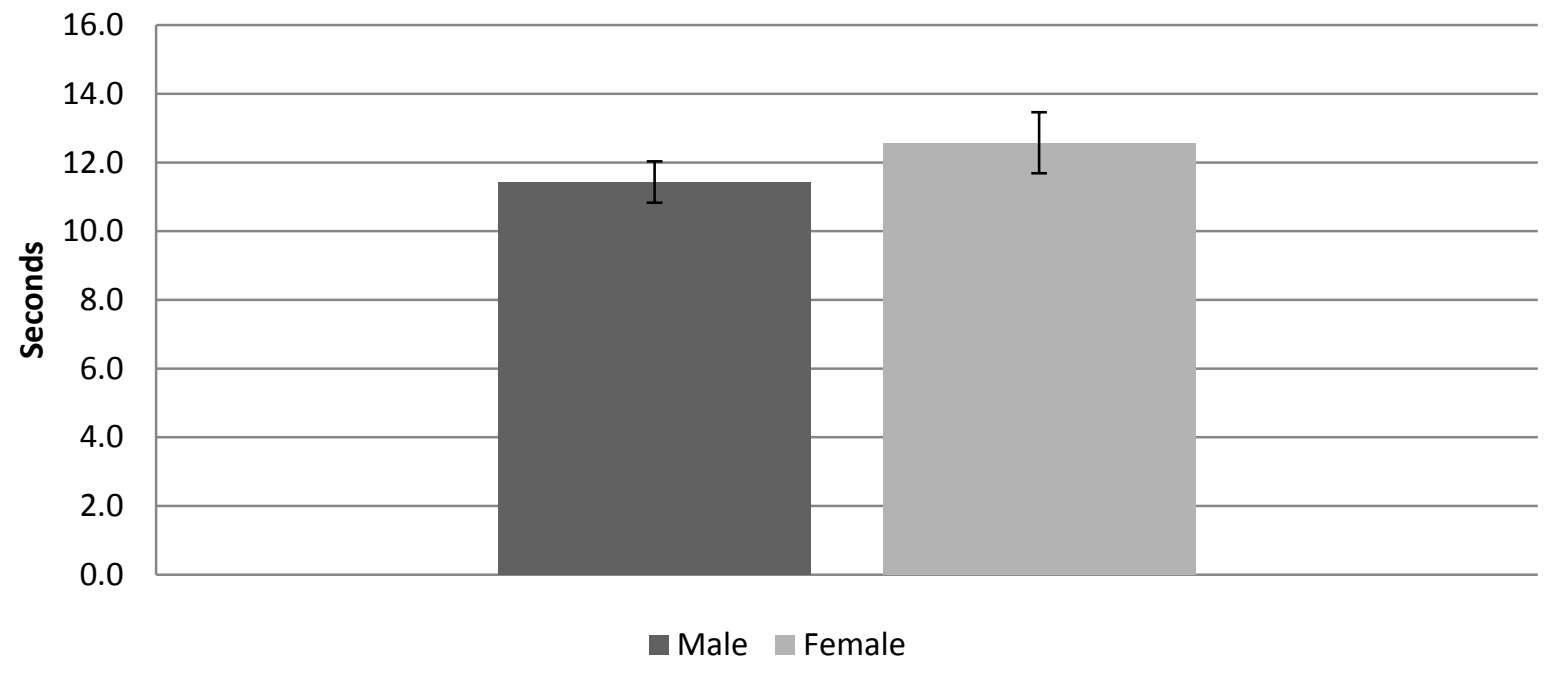

Fig. 3 T-test results. Male scores were significantly less than females $P<0.01$.

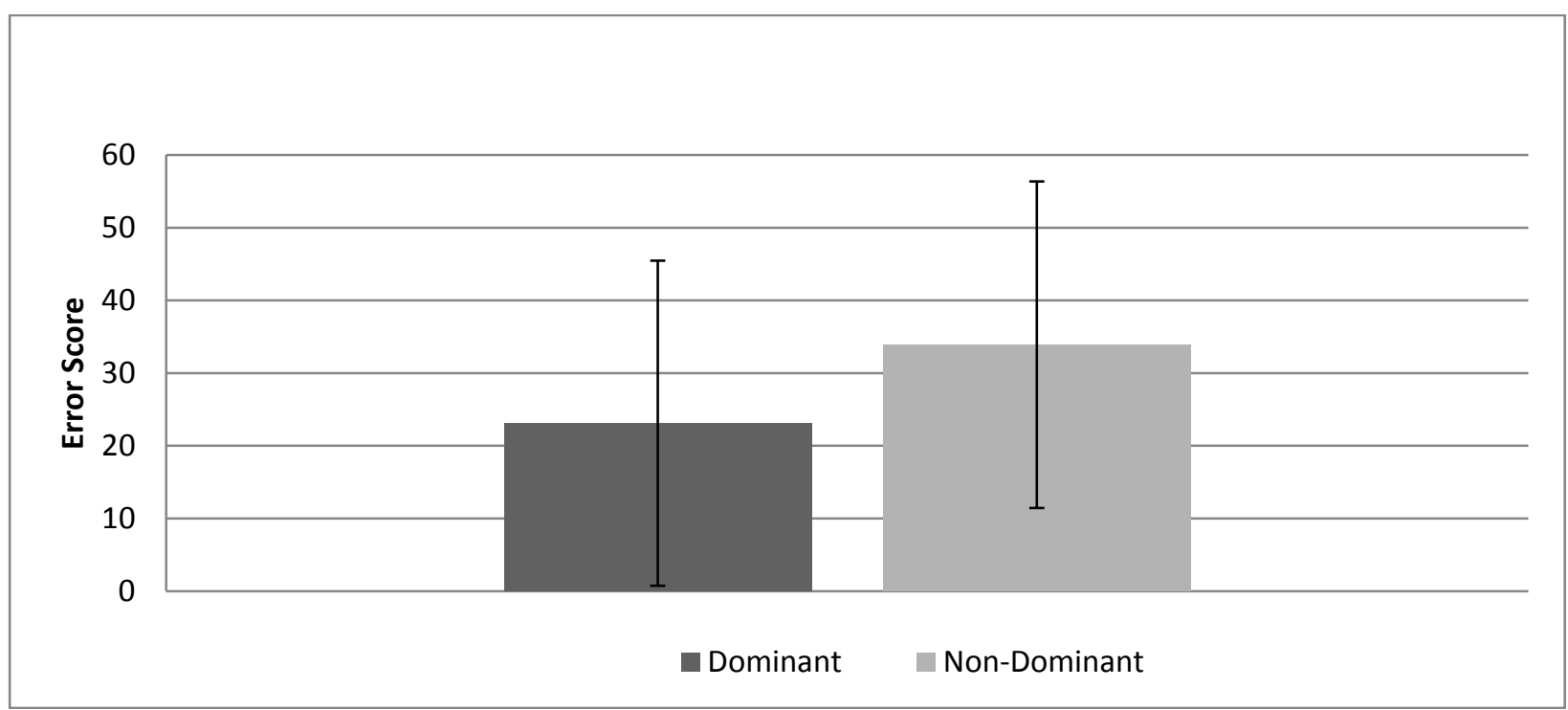

Fig. 4 MBASS test results-male participants. 


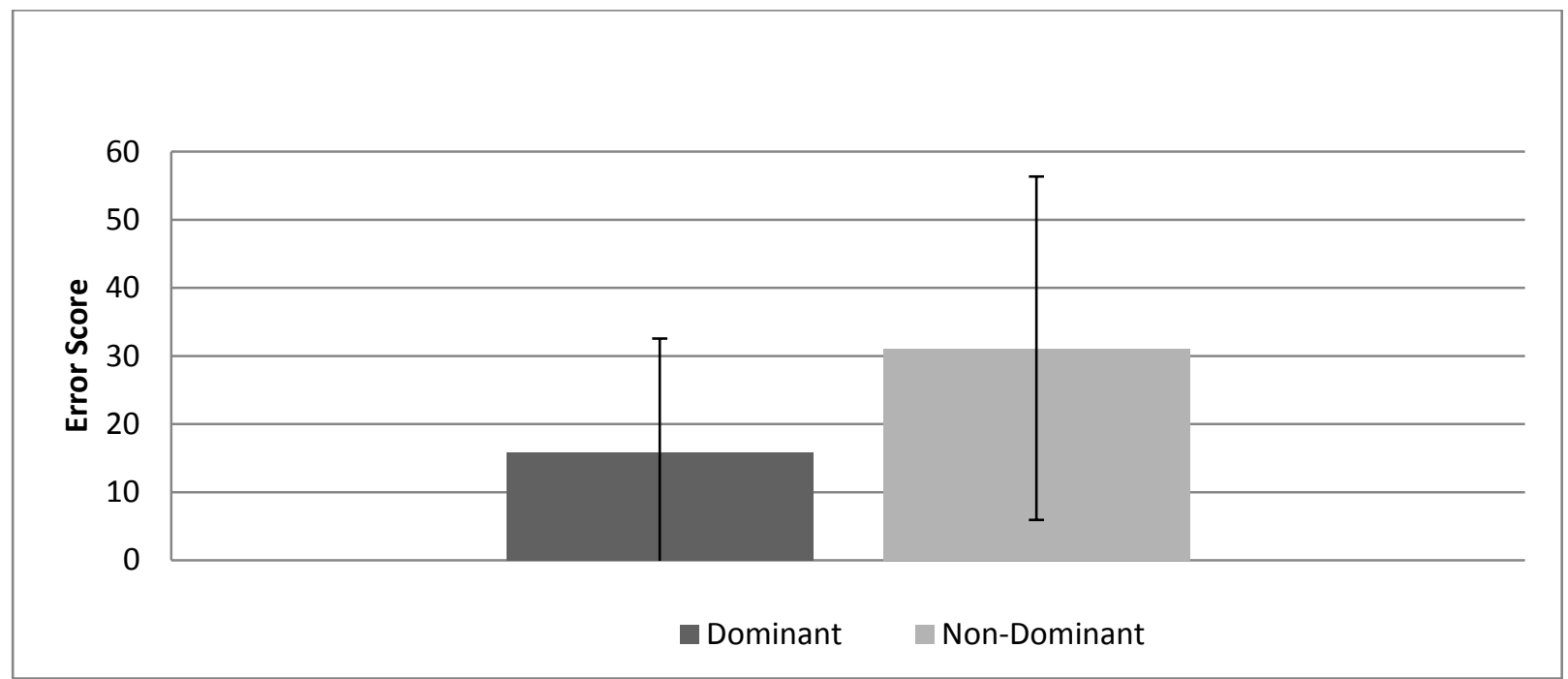

Fig. 5 MBASS test results—female participants.

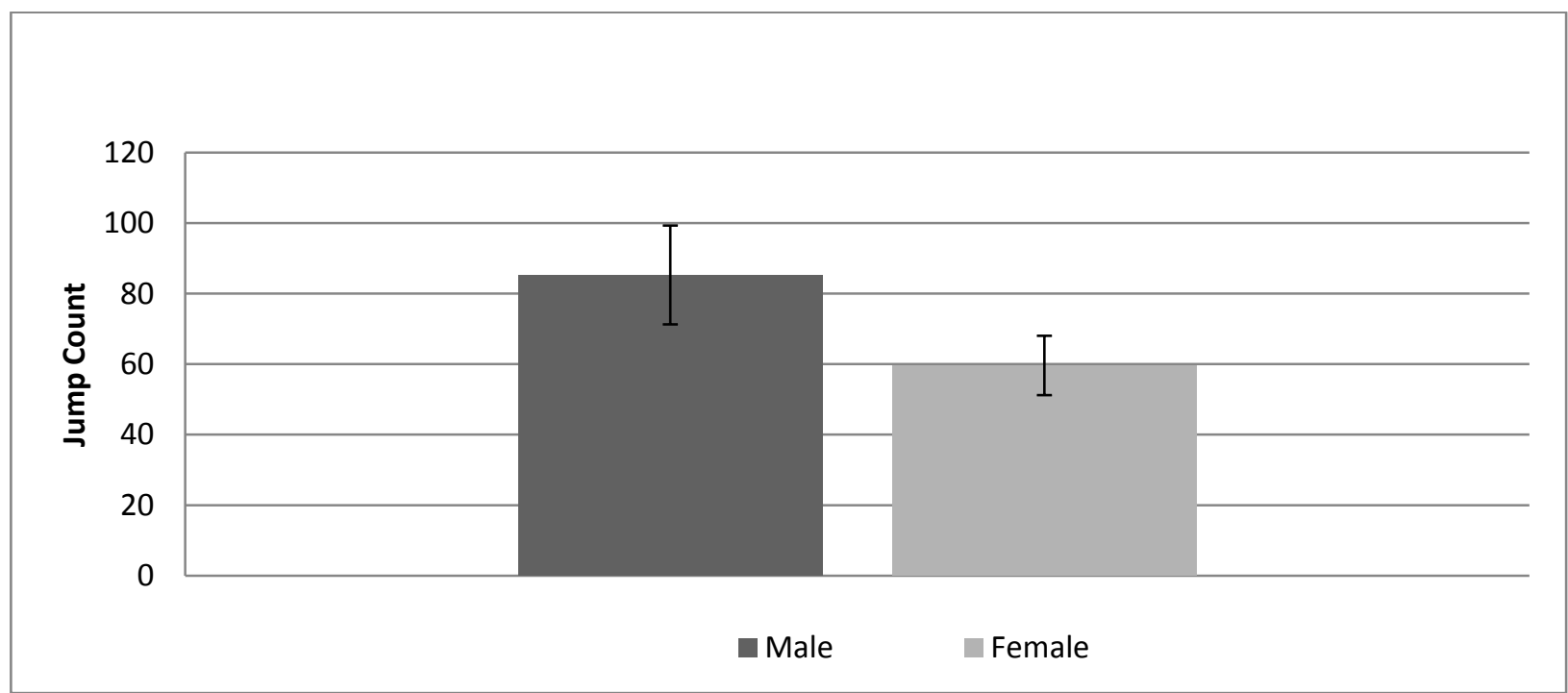

Fig. 6 Endurance hurdle test. Female scores were significantly less than males $P<0.01$.

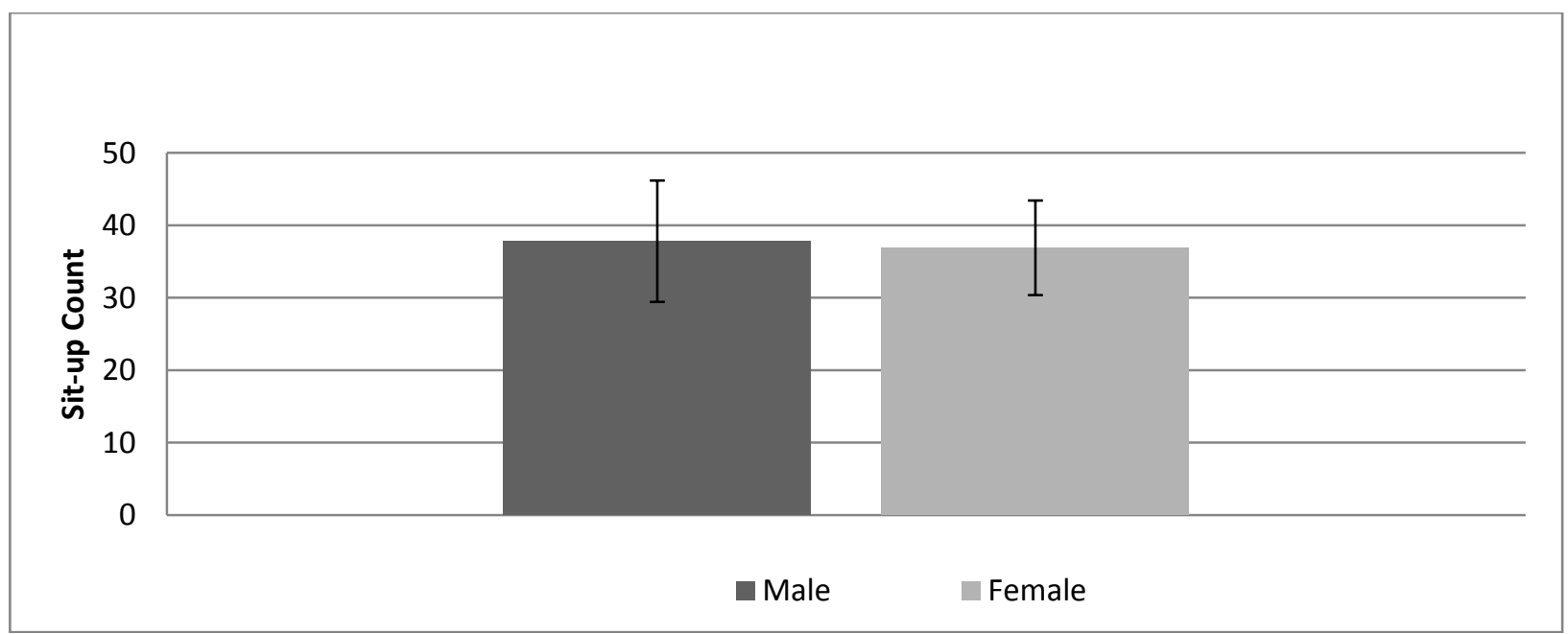

Fig. 7 One-minute sit-up test. 
Table 2 Leg power test.

\begin{tabular}{lll}
\hline Measurement & Female $(n=9)$ & Male $(n=10)$ \\
\hline Jump height $(\mathrm{cm})$ & $36.7 \pm 3.8^{*}$ & $56.7 \pm 9.3$ \\
Pmax $(\mathrm{W})^{\mathrm{a}}$ & $2,634.6 \pm 350.1$ & $4,402.9 \pm 722.7$ \\
Pmean $(\mathrm{W})^{\mathrm{b}}$ & $778.2 \pm 216.1$ & $1,538.16 \pm 334.4$ \\
Pmax $\left(\mathrm{W}^{*} \mathrm{~kg}^{-1}\right)$ & $43.7 \pm 4.4^{*}$ & $58.7 \pm 8.5$ \\
Pmean $\left(\mathrm{W}^{*} \mathrm{~kg}^{-1}\right)$ & $12.6 \pm 1.8$ & $20.2 \pm 3.0$ \\
\hline
\end{tabular}

${ }^{a}$ Pmax $=$ maximum leg power ${ }^{b}$ Pmean $=$ mean leg power $($ mean $\pm \mathrm{sd}),{ }^{*}$ Significant difference between genders $P<0.01$.

Histograms (not presented here) were visually inspected for normalacy as suggested by McDonald [17]. Only the histograms for the MBASS test deviated substantially from what could be considered a normal distribution. The MBASS histograms were positively skewed (dominant and non-dominant leg) for both the male and female participants. Table 2 provides leg lower output measures.

\section{Discussion}

The purpose of this study was to obtain anthropometric and physical fitness data for elite boardercross snowboard athletes in order to allow coaches and athletes to set training goal benchmarks and to assist coaches in identifying individuals who have potential to succeed at a high level of competition. To our knowledge, there are only two prior studies that have attempted to characterize physical attributes of elite snowboarders $[6,7]$. Our study attempted to build on these previous efforts as well address the call for further research by Ruotsalainen [18]; who indicated that research needs to be conducted in the areas of dynamic balance, speed, agility, and muscle power endurance.

Our study focused on measuring height, weight, body composition, BMI, dynamic balance (MBASS test), lower body power (vertical jump), speed and agility (T-Test), lower body muscular endurance (soft hurdle test), and core endurance (one minute sit-up test) of elite boardercross snowboarders. Common field tests were used to quantify parameters of physical fitness, as opposed to the previous research efforts $[6,7]$ which relied upon laboratory based tests. We felt this was a strength of our study in that most coaches and athletes do not have access to research or performance labs. The utilization of field tests allow coaches and athletes to replicate the tests used in this study and compare their results to those contained in this article.

Within the sample studied, most of the athletes were similar in height, mass, and percentage body fat compared to others of the same gender. However, two female participants had a higher percentage of body fat than expected. Body measurement averages were very similar to the body measurements of the 2009 Austrian National Snowboard Team (average male participant's body height in this study and the Austrian study was $176.4 \mathrm{~cm}$ and $177.0 \mathrm{~cm}$ respectively) [6]. The mean body mass of male participants in this study and in the Austrian study were identical $(75.4 \mathrm{~kg})$. Average measurements for females were also similar with average body height of $164.1 \mathrm{~cm}$ and $164.0 \mathrm{~cm}$ in American and Austrian snowboarders, respectively [6]. Average female body mass was $60.7 \mathrm{~kg}$ and $59.7 \mathrm{~kg}$ in American and Austrian snowboarders, respectively [6]. These numbers are also very similar to the average general population height for 19 year olds (males 176.7 $\mathrm{cm}$ and females $163.1 \mathrm{~cm}$ ) [19].

The study participants had a slightly lower body mass than the average general population for 19 year olds, which is $83.4 \mathrm{~kg}$ for males and $71.1 \mathrm{~kg}$ for females [19]. The body fat percentage of the participants was lower than average for both males and females. The average male participant's body fat of $11.6 \%$ is comparable to NCAA Division I wrestlers $(11.0 \%)$ [20]. The average female participant's body fat of $18.8 \%$ was similar to NCAA Division I female gymnasts (19.1\%) [21]. The body mass index (BMI) was in the normal range $(\mathrm{BMI}=18.5-24.9)$ for both the 
male $(22.5 \pm 2.8)$ and female $(24.22 \pm 3.3)$ participants [22].

The results from the leg power test were also fairly consistent with the exception of one male participant outlier. To our knowledge, no other study has reported leg power using the Harman formula in this population [12]. Using the range of jump height and body mass reported in the Platzer study [6], the 2009 Austrian National Snowboard Team range of peak power $/ \mathrm{kg}$ would be calculated as: $38.5-52.0 \mathrm{~W} / \mathrm{kg}$ (males) and 29.3-43.8 (females) and are comparable to the values $(58.4 \mathrm{~W} / \mathrm{kg}$ males) and (43.7 W/kg females) in the current study [6]. For additional comparison, the peak power/kg output for 15-20 year old male soccer players using the Harman formula has been estimated to be $39.8 \mathrm{~W} / \mathrm{kg}$ of body mass [23].

The MBASS balance test had a large range of results (MBASS: 0-80 female, 3-77 male). The current study hypothesized that there would be notable uniformity between the participants' balance. However, the result of this test indicates the opposite. In fact, the standard deviation for the male participants on this test was greater than the mean error score. This may be due to having the athlete's perform a test balancing on one leg rather than on two as would generally be done with snowboarding. The participants scored extremely well for dynamic balance when compared to recreationally active individuals as documented by Riemann and colleagues [11] in which the combined male and female average score was 51.0. The present study found the average male boardercross dominant leg score was $23.1 \pm 22.4$ and average score of female boardercross dominant leg score was $15.9 \pm 16.7$. Although results indicate a high degree of balance in boardercross snowboarders, further study needs to be done to test for balance while on two feet.

The results from the participant's T-test were not very impressive when compared to norms from other sports. For example, the average T-test score for male elite high school soccer players is 10.18 seconds compared to the average male boardercross score of
11.43, and the average female NCAA Division I volleyball T-test score is 11.16 compared the average female boardercross score of 12.57 [19, 24]. Boardercross snowboarders do not compete in a manner that is specific to the physical demands of completing the T-test. The T-test requires sprinting followed by stops and rapid changes in direction. Boardercross snowboarder competition requires change in directions rapidly but not sprinting and stopping. As such, the T-test might not be a valuable assessment tool for boardercross snowboarders.

Although the data from the leg endurance test has not been compared to the general population or athletes of other sports, the mean score for males was 85.30 jumps and two male participants completed over 100 jumps in one minute. This equates to 1.67 jumps per second. The highest number of jumps for any female participants was 75 , which equates to 1.25 jumps per second. It also should be noted that participants that were shorter had a more difficult time continuing to jump over the 12 inch hurdle due to leg length. This may account for some of the deviation in scores, particularly with the female participants who were shorter than the male participants. Future studies might consider adjusting the hurdle height to a percentage of participant's body height. Due to the increased duration of the test, to our knowledge, there is no comparable data from other sports for this endurance jump test.

The sit-up test was the last test performed and the participants may have been fatigued due to the previous tests, particularly the leg endurance test. Although the data provides a starting point for discussion, performing the sit-up test without prior fatigue may yield more useful results. When compared to female NCAA Division I lacrosse players, both the male and female participants of this study performed significantly fewer sit-ups within a one minute period. Female lacrosse NCAA Division I players average 47.4 sit-ups while the male participants of this study averaged 37.8 sit-ups and the female participants averaged 36.9 sit-ups [25]. Core endurance (i.e. trunk 
muscular endurance) should be considered an important aspect of boardercross snowboarding performance and assessing core endurance via the one minute sit-up test would seem to be prudent.

The current study is preliminary in nature and additional research is required in order to directly link the physical characteristics collected in this study with actual NorAm competition rankings. With that said, the potential practical application of this data is that it may serve to illustrate benchmarks for future boardercross snowboarders. It may also prove useful in identifying individuals with potential to succeed as competitive boardercross snowboarders.

The information collected during the current study appears to indicate that highly trained boardercross snowboarders have a high level of leg power and dynamic balance. It also indicates that having above normal speed and agility are not essential to competing at a high level of boardercross competition. The data culled in this study seems counter intuitive in regards to core strength in boardercross snowboarders. It seems logical to assume that boardercross snowboarders must have high levels of core endurance to compete at an elite level, yet the results of the sit-up test in the current study indicate otherwise. Lastly, although comparable data for a one minute leg endurance test is unavailable, the pace at which the participants continued jumping during the test seems to indicate that leg endurance (lower body muscular endurance) is an important parameter of fitness related to boardercross snowboarding.

A clear limitation of this study is the small sample size; however, there are only so many elite level boardercross snowboarders in the USA. There is 7 NorAm level boardercross snowboarder teams in the Western US (comprised of approximately 50-70 athletes). Hence, the current sample of participants $(n=$ 19) represents about $27 \%-38 \%$ of all elite boardercross snowboarders in the Western US. Future studies should include: the comparison of NorAm level athletes with World Cup athletes, as well as the comparison of boardercross snowboarders to freestyle and half pipe snowboarders. Future studies should also consider using a two-leg balance test as well as quantifying the relationship between physical performance measures (as collected in this study) and actual NorAm competition rankings.

\section{Conclusions}

Within the parameters of this study NorAm level boardercross snowboarders are:

(1) average for height and mass when compared to the general population,

(2) comparably lean (percent body fat) to other collegiate athletes,

(3) have a normal BMI classification,

(4) above average with regards to leg power, dynamic balance, and lower body muscular endurance.

\section{References}

[1] Back, J., Kang, H., Son, W., Jo, S., Lee, J., and Panday, S. 2014. "Three Dimensional Analysis of Carving Front Turn of Alpine and Boarder-Cross Snowboarder.” International Journal of Multimedia and Ubiquitous Engineering 9 (10): 399-408.

[2] Boardercross. 2014. Accessed December 12, 2014. http://en.wikipedia.org/wiki/Boardercross

[3] Ransdell, L., and Murray, T. 2011. "A Physical Profile of Elite Female Ice Hockey Players from the USA." The Journal of Strength and Conditioning Research 25 (9): 2358-63.

[4] Battista, R., Pivarnik, J., Dummer, G., Sauer, N., and Malina, R. 2007. "Comparisons of Physical Characteristics and Performance among Female Collegiate Rowers.” Journal of Sports Sciences 25: 651-7.

[5] Turner, A., Walker, S., Stembridge, M., Coneyworth, P., Reed, G., Birdsey, L., and Moody, J. 2011. "A Testing Battery for the Assessment of Fitness in Soccer Players." Strength and Conditioning Journal 33 (5): 29-39.

[6] Platzer, H., Raschner, C., Patterson, C., and Lembert, S. 2009. "Comparison of Physical Characteristics and Performance among Elite Snowboarders." Journal of Strength and Conditioning Research 23 (5): 1427-32.

[7] Żebrowska, A., Żyła, D., Kania, D., and Langfort, J. 2012. "Anaerobic and Aerobic Performance of Elite Female and Male Snowboarders." Journal of Human Kinetics 34 (2012): 81-8.

[8] Armstrong, L., Balay, G., Berry, M., Davis, S., Davy, B., 
Frankin, B., and Wallace, J. 2006. ACSM's Guidelines for Exercise Testing and Prescription (7th ed.), edited by Whalay, M., Brubaker, P., and Otto, R. Philadelphia: Lippincott Williams \& Wilkins.

[9] Shim, A., Cross, P., Norman, S., and Hauer, P. 2014. "Assessing Various Body Composition Measurements as an Appropriate Tool for Estimating Body Fat in National Collegiate Athletic Association Division I Female Collegiate Athletes." American Journal of Sports Science and Medicine 2 (1): 1-5.

[10] Flanagan, S. 2012. "Balance and Stability." In NSCA's Guide to Tests and Assessments, edited by Miller, T. Champaign, IL: Human Kinetics, 304-13.

[11] Riemann, B., Caggiano, N., and Lephart, S. 1999. "Examination of a Clinical Method of Assessing Postural Control during a Functional Performance Task." Journal of Sport Rehabilitation 8: 171-83.

[12] Harman, E., Rosenstein, M., Frykman, P., Rosenstein, R., and Kraemer, W. 1991. "Estimation of Human Power Output from Vertical Jump." Journal of Applied Sport Science Research 5 (3): 116-20.

[13] Pauole, K., Madole, K., Garhammer, J., Lacourse, M., and Rozenek, R. 2000. "Reliability and Validity of the T-test as a Measure of Agility, Leg Power, and Leg Speed in College-aged Men and Women." Journal of Strength and Conditioning Research 14 (4): 443-50.

[14] Semenick, D. 1990. "Tests and Measurements: The T-test." National Strength \& Conditioning Association Journal 12 (1): 36-7.

[15] Pupo, J., Gheller, R., Dias, J., Rodacki, A., Moro, A., and Santos, S. 2013. "Reliability and Validity of the 30-s Continuous Jump Test for Anaerobic Fitness Evaluation." Journal of Science and Medicine in Sport 17 (6): 650-5.

[16] Waldhelm, A., and Li, L. 2012. "Endurance Tests are the Most Reliable Core Stability Related Measurements." Journal of Sport and Health Science 1 (2): 121-8.

[17] McDonald, J. H. 2014. Handbook of Biological Statistics, 3rd Ed. Sparky House Publishing, Baltimore, Maryland.

[18] Ruotsalainen, I. 2012. "Training and Periodization for Snowboard Cross, Parallel Slalom and Parallel Giant Slalom." Science of Sports Coaching and Fitness Testing Coaching Seminar LBIA016. Department of Biology of Physical Activity, University of Jyvaskyla.

[19] Hoffman, J. 2006. Norms for Fitness, Performance, and Health. Champaign, IL: Human Kinetics.

[20] Clark, R. R., Sullivan, J.C., Bartok, C., and Schoeller, D. A. 2003. "Multicomponent Cross-validation of Minimum Weight Predictions for College Wrestlers." Medicine Science in Sports Exercise 35: 342-7.

[21] Fornetti, W., Pivarnik, J., Foley, J., and Fliechtner, J. 1999. "Reliability and Validity of Body Composition Measures in Female Athletes." Journal of Applied Physiology 87: 1114-22.

[22] Flegal, K. M., Kit, B. K., Orpana, H., and Graubard, B. I. 2013. "Association of All-cause Mortality with Overweight and Obesity Using Standard Body Mass Index Categories: A Systematic Review and Meta-analysis." Journal of the American Medical Association 309 (1): 71-82.

[23] Quagliarella, L., Sasanelli, N., Belgiovine, G., Moretti, L., and Moretti, B. 2011. "Power Output Estimation in Vertical Jump Performed by Young Male Soccer Players." Journal of Strength and Conditioning Research 25 (6): 1638-46.

[24] Fry, A., Kraemer, W., Weseman, C., Conroy, B., Gordon, S., Hoffman, J., and Maresh, C. 1991. "The Effects of an off-Season Strength and Conditioning Program on Starters and non-Starters in Women's Intercollegiate Volleyball." Journal of Applied Sports Science Research 5: 174-81.

[25] Enemark-Miller, E., Seegmiller, J., and Rana, S. 2009. "Physiological Profile of Women's Lacrosse Players." Journal of Strength and Conditioning Research 23 (1): $39-43$. 